\title{
Mutagenesis
}

\section{Structural Analysis of a GalNAc-T2 Mutant Reveals an Induced-Fit Catalytic Mechanism for GaINAc-Ts}

\author{
Matilde de las Rivas ${ }^{+}{ }^{[a]}$ Helena Coelho ${ }^{+},{ }^{[b, c]}$ Ana Diniz, ${ }^{[b]}$ Erandi Lira-Navarrete, ${ }^{[d]}$ \\ Ismael Compañón, ${ }^{[e]}$ Jesús Jiménez-Barbero, ${ }^{\left[{ }^{[c},{ }^{f]}\right.}$ Katrine T. Schjoldager, $^{[\mathrm{d}]}$ Eric P. Bennett, ${ }^{[\mathrm{d}]}$ \\ Sergey Y. Vakhrushev, ${ }^{[\mathrm{d}]}$ Henrik Clausen, ${ }^{[\mathrm{d}]}$ Francisco Corzana ${ }^{[\mathrm{e}]}$ Filipa Marcelo, ${ }^{*[\mathrm{~b}]}$ and \\ Ramon Hurtado-Guerrero*[a, g]
}

Abstract: The family of polypeptide $N$-acetylgalactosamine (GalNAc) transferases (GalNAc-Ts) orchestrates the initiating step of mucin-type protein O-glycosylation by transfer of GalNAc moieties to serine and threonine residues in proteins. Deficiencies and dysregulation of GalNAc-T isoenzymes are related to different diseases. Recently, it has been demonstrated that an inactive GalNAc-T2 mutant (F104S), which is not located at the active site, induces low levels of highdensity lipoprotein cholesterol (HDL-C) in humans. Herein, the molecular basis for F104S mutant inactivation has been deciphered. Saturation transfer difference NMR spectroscopy experiments demonstrate that the mutation induces loss of binding to peptide substrates. Analysis of the crystal structure of the F104S mutant bound to UDP-GalNAc (UDP $=$ uri- dine diphosphate), combined with molecular dynamics (MD) simulations, has revealed that the flexible loop is disordered and displays larger conformational changes in the mutant enzyme than that in the wild-type (WT) enzyme. ${ }^{19} \mathrm{~F}$ NMR spectroscopy experiments reveal that the WT enzyme only reaches the active state in the presence of UDP-GalNAc, which provides compelling evidence that GalNAc-T2 adopts a UDP-GalNAc-dependent induced-fit mechanism. The F104S mutation precludes the enzyme from achieving the active conformation and concomitantly binding peptide substrates. This study provides new insights into the catalytic mechanism of the large family of GaINAc-Ts and how these enzymes orchestrate protein O-glycosylation.

\section{Introduction}

Mucin-type ( $\mathrm{N}$-acetylgalactosamine (GalNAc)-type) O-glycosylation is the most differentially and complex regulated type of protein glycosylation, and likely the most abundant, with over $80 \%$ of all proteins predicted to be O-glycosylated. ${ }^{[1]}$ This posttranslational modification is initiated by a large family (20 in humans) of enzymes named polypeptide $\mathrm{N}$-acetylgalactosaminyl transferases (GalNAc-Ts), which catalyze the attachment of a GalNAc residue of the substrate UDP-GalNAc (UDP $=$ uridine diphosphate) to Ser/Thr residues of the peptide backbone.

Although these enzymes have a partial overlap in recognition and glycosylation of substrates, a subset of glycosylation [a] M. d. I. . Rivas, ${ }^{+}$Dr. R. Hurtado-Guerrero Instituto de Biocomputación y Fisica de Sistemas Complejos (BIFI) BIFI-IQFR (CSIC) Joint Unit, Universidad de Zaragoza 50018 Zaragoza (Spain) E-mail: rhurtado@bifi.es

[b] H. Coelho, ${ }^{+}$A. Diniz, Dr. F. Marcelo UCIBIO, REQUIMTE, Departamento de Química Faculdade de Ciências e Tecnologia Universidade Nova de Lisboa 2829-516 Caparica (Portugal) E-mail:filipa.marcelo@fct.unl.pt

[c] H. Coelho, ${ }^{+}$Prof. J. Jiménez-Barbero CIC bioGUNE, Bizkaia Technology Park, Building 801A 48170 Derio (Spain) and

Department of Organic Chemistry II Faculty of Science \& Technology University of the Basque Country 48940 Leioa, Bizkaia (Spain) [d] E. Lira-Navarrete, Dr. K. T. Schjoldager, Dr. E. P. Bennett, Dr. S. Y. Vakhrushev, Prof. H. Clausen

Copenhagen Center for Glycomics

Department of Cellular and Molecular Medicine, School of Dentistry University of Copenhagen

Copenhagen (Denmark)

[e] I. Compañón, Dr. F. Corzana

Departamento de Química, Universidad de La Rioja Centro de Investigación en Síntesis Química E-26006 Logroño (Spain)

[f] Prof. J. Jiménez-Barbero Ikerbasque, Basque Foundation for Science Maria Diaz de Haro 13 48009 Bilbao (Spain)

[g] Dr. R. Hurtado-Guerrero Fundación ARAID, 50018, Zaragoza (Spain)

$\left.{ }^{+}\right]$These authors contributed equally to this work.

$\square$ Supporting information and the ORCID identification number(s) for the au-

iD thor(s) of this article can be found under: https://doi.org/10.1002/chem.201800701. 
sites is subjected to site-specific O-glycosylation by individual GalNAc-Ts. For instance, GalNAc-T3 is responsible for the sitespecific glycosylation of Thr178 of FGF23; a major regulator of phosphate homeostasis. ${ }^{[2]}$ This site-specific glycosylation of Thr178 prevents the inactivation of FGF23 by proprotein convertase proteases; ${ }^{[3]}$ thus mutations in GalNAc-T3 leading to a decrease or complete abolishment of its activity are known to cause familial tumoral calcinosis. ${ }^{[3]}$ Through a similar mechanism, we have recently demonstrated that the loss of GalNAcT2 function lowers high-density lipoprotein cholesterol (HDLC) levels in humans. ${ }^{[4]}$ We also identified two independent deficiencies in the GALNT2 gene, and one of these involved the homozygous missense mutation F104S, ${ }^{[4]}$ which was not predicted to be deleterious based on conservation and prior structural models of the enzyme. ${ }^{[5]}$ These examples illustrate how GalNAc-T isoforms, with seemingly many roles in protein glycosylation, have limited nonredundant biological functions. ${ }^{[3,4]}$

From a structural perspective, GalNAc-Ts are unique among glycosyltransferases because, in addition to their N-terminal catalytic domain, they possess a unique C-terminal lectin domain; both domains are connected by a short flexible linker (Figure $1 \mathrm{a}$ and Figure S1 in the Supporting Information). There is also an interesting structural feature in the catalytic domains

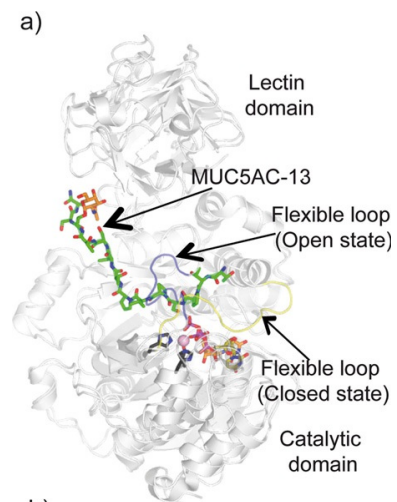

b)

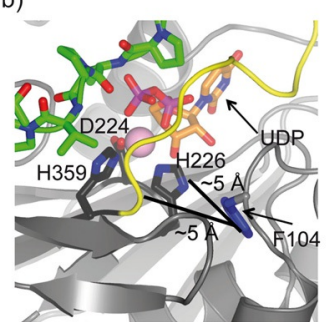

Figure 1. States of the flexible loop and location of Phe104: a) Superposition of the overall crystal structure of GaINAc-T2 in complex with UDP and the glycopeptide MUC5AC-13 ${ }^{[5]}$ (closed conformation shown in white; see PDB entry 5AJP), with the crystal structure of GalNAc-T2 in complex with UDP ${ }^{[7 b]}$ (open conformation also shown in white; see PDB entry 2FFV). The GaINAc moiety of MUC5AC-13 is colored in orange. UDP and MUC5AC-13 are depicted as orange and green carbon atoms, respectively. The $\mathrm{Mn}^{2+}$ binding $\mathrm{D}_{224} \mathrm{xH}_{226}$ motif and His359 are shown as black carbon atoms. The flexible loop is depicted in blue (open conformation) and yellow (closed conformation) for the PDB entries 2FFV and 5AJP, respectively. $\mathrm{Mn}^{2+}$ is shown as a pink sphere. b) Close-up view of the active site (closed conformation; PDB entry 5AJP), showing the distance of Phe104 (blue) to the flexible loop (yellow) and His226 (black). The backbone structure is shown in gray, whereas the other structural features and amino acids are shown in the same colors as those used in (a). of these enzymes, a flexible loop, which comprises residues Val360 to Gly372 in GalNAc-T2. This loop may adopt different conformations during the catalytic cycle; thus rendering the enzyme catalytically inactive or active ${ }^{[5,6]}$ Furthermore, the flexible loop dynamics are coupled to mobility of the key catalytic residue Trp331, which can adopt "in" (inside of the active site) and "out" (outside of the active site) conformations that, in turn, are also associated with the active or inactive states of GalNAc-T2, respectively. ${ }^{[5,6]}$ Crystal structures of GalNAc-Ts can be used as a platform to infer how mutations of these enzymes might lead to loss of function. ${ }^{[5-7]}$ However, this is not always straightforward and further experimental work in solution to infer the dynamic behavior of the global system is required. The F104S mutant in GalNAc-T2 precisely illustrates this idea because Phe104 is not located at the active site, but placed at a distance of about $5 \AA$ from the flexible loop and the critical $\mathrm{Mn}^{2+}$ binding site, which is formed by the $\mathrm{D}_{224} \mathrm{xH}_{226}$ residues and His359 (Figure $1 \mathrm{~b}$ ). ${ }^{[5]}$ Thus, it is not clear how mutation of Phe to Ser impairs the catalytic activity of GalNAc-T2.

Herein, we show that the F104S mutation in GalNAc-T2 constrains the flexible loop and renders the enzyme locked in an inactive state unable to bind the acceptor peptide substrate. We have combined saturation transfer difference (STD) NMR spectroscopy, ${ }^{19} \mathrm{~F}$ NMR spectroscopy, X-ray crystallography, and molecular dynamics (MD) simulations to demonstrate that Phe104 fine-tunes the dynamic behavior of the flexible loop by establishing a $\mathrm{CH}-\pi$ interaction with the side chain of Arg362, which is located at the flexible loop. This interaction appears to be key to maintaining the flexible loop in the required closed conformation that leads to the active state of the enzyme. Therefore, the inability of the mutant to adopt the active state disrupts peptide substrate recognition and prevents O-glycosylation. Finally, we have experimentally demonstrated that GalNAc-T2 adopts a UDP-GalNAc-dependent induced-fit mechanism for catalysis and suggest that the behavior of the flexible loop can be extrapolated to the rest of the members of the GalNAc-T family.

\section{Results and Discussion}

\section{Lack of GalNAc-T2 F104S mutant binding to peptides}

The available data based on kinetic assays of the F104S mutant cannot explain the molecular basis of the inactivation of the GalNAc-T2 mutant F104S against protein substrates. ${ }^{[4]}$ Because Phe104 is not located at the active site (Figure $1 \mathrm{~b}$ ), its mutation to Ser must induce conformational changes of the residues located in the active site; this affects either binding of the mutant to the substrates or catalytic turnover. To rule out one of these two hypotheses, we have determined binding of the GalNAc-T2 wild-type (WT) enzyme and the F104S mutant to UDP-GalNAc and a peptide substrate by applying tryptophan fluorescence spectroscopy and STD-NMR spectroscopy experiments. In addition, we have also conducted a thermal shift-assay experiment on both enzymes to evaluate the differences in protein stability. ${ }^{[8]}$ The data in Figure 2 show that the WT enzyme is more stable than the F104S mutant (denatura- 
a)

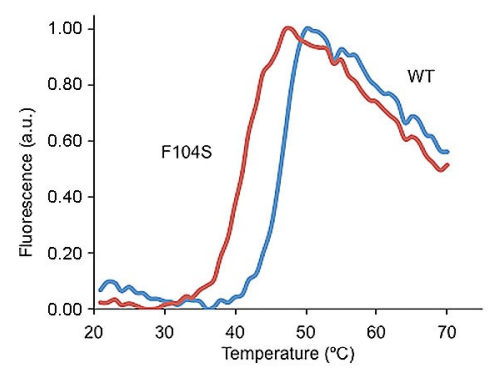

b)

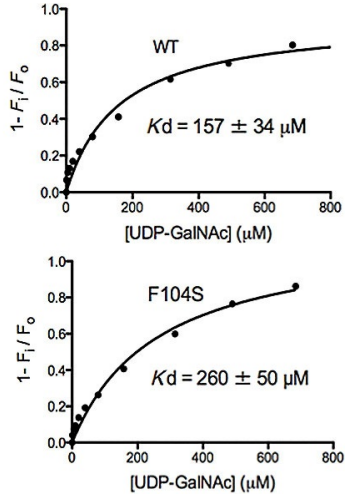

Figure 2. Stability and binding properties of the WT enzyme and the F104S mutant. a) Thermal denaturation curves of the WT enzyme and the F104S mutant, as monitored by 1-anilino-8-naphthalene sulfonate (ANS) fluorescence. b) $K_{d}$ values for sugar nucleotide binding determined from the tryptophan fluorescence intensity as a function of UDP-GalNAc concentrations.

tion temperatures, $T_{0}$, of $(47 \pm 0.09)$ and $(42 \pm 0.05){ }^{\circ} \mathrm{C}$, respectively), which implies that mutation leads to a significant decrease in the stability of the mutant (Figure 2a). Tryptophan fluorescence spectroscopy analysis of UDP-GalNAc binding revealed that both the WT enzyme and the F104S mutant bound to the donor sugar nucleotide; the $K_{d}$ value of UDP-GalNAc to the mutant was 1.7-fold higher than that of the $K_{d}$ determined for the WT enzyme (Figure $2 b$ and Figure S2 in the Supporting Information). In contrast, STD-NMR spectroscopy experiments recorded for the peptide substrate, MUC5AC (GTTPSPVPTTSTTSA), only showed STD response in presence of WT GalNAC-T2 (Figure S3 in the Supporting Information). No STD enhancements were observed for MUC5AC in the presence of the mutant F104S (Figure S3 in the Supporting Information). This result indicates that the mutant is not able to properly recognize and bind the peptide substrate; thus explaining the previously observed inactivity of the mutant towards protein substrates, such as phospholipid transfer protein (PLTP) and ApoC-III. ${ }^{[4]}$ In addition, the WT enzyme showed clear STD-NMR signals for the protons of valine and proline amino acids from the sequence PSPVPI (in which the underlined Thr is the main acceptor site on this peptide for GalNAc-T2) relative to the rest of the peptide sequence (Figure S4 in the Supporting Information). The identified STD-NMR epitope is consistent with sequence preferences of GaINAc-T2, particularly with a Pro residue preceding the site of glycosylation. ${ }^{[9,10]}$ Hence, although there are no major differences in UDP-GalNAc recognition between the WT enzyme and F104S mutant, the dramatic differences in activity are accounted for by either the inability or poor affinity of the F104S mutant to bind the peptide substrates.

\section{Phe104 control of the inactive-to-active state transition}

To elucidate the molecular basis for the loss of acceptor peptide substrate binding induced by the F104S mutation, we obtained tetragonal crystals of this mutant in complex with UDP that were subsequently soaked with UDP-GalNAc. The result- ing crystals allowed us to solve the structure at a resolution of $2.70 \AA$ (Table S2 in the Supporting Information). Within the asymmetric unit $(\mathrm{AU})$, two molecules of the F104S mutant were present. The crystal structure shows a compact structure with the typical N-terminal GT-A fold and a C-terminal lectin domain (Figure 3).

The flexible loop in both F104S molecules of the AU is highly disordered (Figures 3-5 and Figure S5 in the Supporting Information), which exposes the substrate UDP-GalNAc to the solvent. In these structures, the flexible loop displays the open conformation, which restrains the enzyme in an inactive state, resembling the structure of the WT enzyme in its inactive state (see PDB entry 2FFV; Figures 3-5). This conformation is opposed to that presenting the active state. In the active state, the flexible loop displays a closed conformation that functions to shield UDP-GalNAc or UDP from the solvent (e.g., see PDB entries 5AJP, 4D0T and 4D0Z; Figure 3). This geometrical arrangement is required for the binding of the peptide/protein substrates. ${ }^{[5,6 c]}$ This closed conformation of the flexible loop is further stabilized by interactions of His365 and Phe369 with

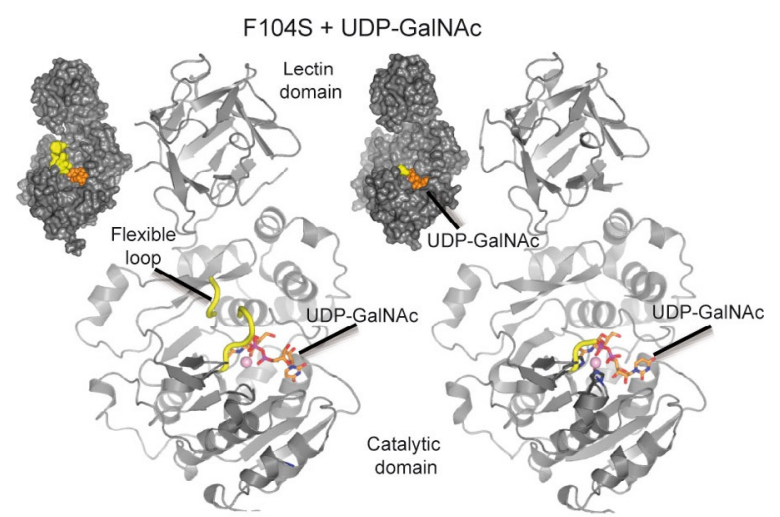

GalNAc-T2 + UDP (2FFV) GalNAc-T2 + UDP + MUC5AC-13 (5AJP)

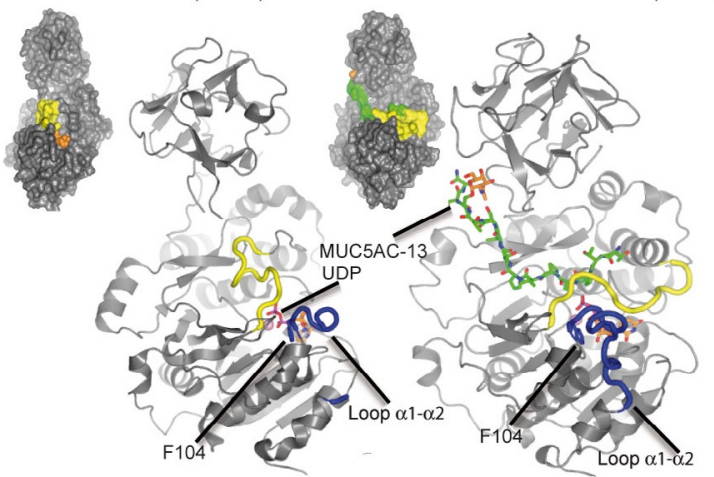

Figure 3. Overall crystal structure of the F104S mutant bound to UDPGalNAc. Visual representation of the overall F104S mutant in complex with UDP-GalNAc and the WT enzyme in complex with either UDP ${ }^{[7 b]}$ (PDB entry $2 \mathrm{FFV}$ ) or UDP/MUC5AC-13 ${ }^{[5]}$ (PDB entry 5AJP). The proteins and GaINAC moiety of MUC5AC-13 are colored in gray and orange, respectively. UDP/ UDP-GaINAC, MUC5AC-13, the flexible loop, and the $\alpha 1-\alpha 2$ loop are depicted as orange, green, yellow, and blue carbon atoms, respectively. The Phe104 and the $\mathrm{Mn}^{2+}$ ion are shown as a blue stick and a pink sphere, respectively. Inset: Surface representation of the above complexes showing inactive and active states; the colors are the same as above. Note that we present the overall structure of both F104S molecules present in the AU because there are some differences between them. 
Trp331 (in-conformation) and by additional interactions with the donor substrate UDP-GalNAc (Figure 5). ${ }^{[6]]}$ The fully active state can only be reached if both the flexible loop and Trp331 adopt the closed geometry and the in-conformation, respectively.

UDP-GalNAc in the inactive F104S mutant is shown to adopt two potential conformations, as previously described for UDP (Figures 3-5). ${ }^{[5,7 b]}$ The first conformation is that in which the uridine moiety is bound in an "inverted" conformation, which is compatible with UDP-GalNAc entrance into the active site. The second conformation is the enzyme in an active state, with a conformation suited for catalysis (see also PDB entry 5AJP; Figure 4). It should also be noted that the crystal structure of GalNAc-T2 in complex with UDP shown in PDB entry 2FFV shows the uridine moiety in the inverted conformation, although this geometry is likely to be related to product release (Figure 4).

A detailed analysis of the F104S mutant structure reveals a lack of density for Ser104 and for most of the residues of the loop between helices $\alpha 1$ and $\alpha 2$ (named hereafter $\alpha 1-\alpha 2$ loop). In the WT enzyme, Phe104 establishes hydrophobic and stacking interactions with Ala151/lle256/Val360 and Phe261; this is likely to stabilize the location of both $\alpha 1-\alpha 2$ and the flexible loops in the inactive state (Figure 4). The disordered states of both loops in the inactive mutant might also explain why this structure is less stable than that of the WT enzyme (see above). In the active state of the enzyme, Phe104 also establishes a $\mathrm{CH}-\pi$ interaction with the side chain of Arg362 located in the flexible loop (Figure 4). This stabilizing interaction appears to be a key feature that renders the closed conformation of the flexible loop. In contrast, the polar Ser104 residue is likely to disrupt interactions with the hydrophobic/aromatic

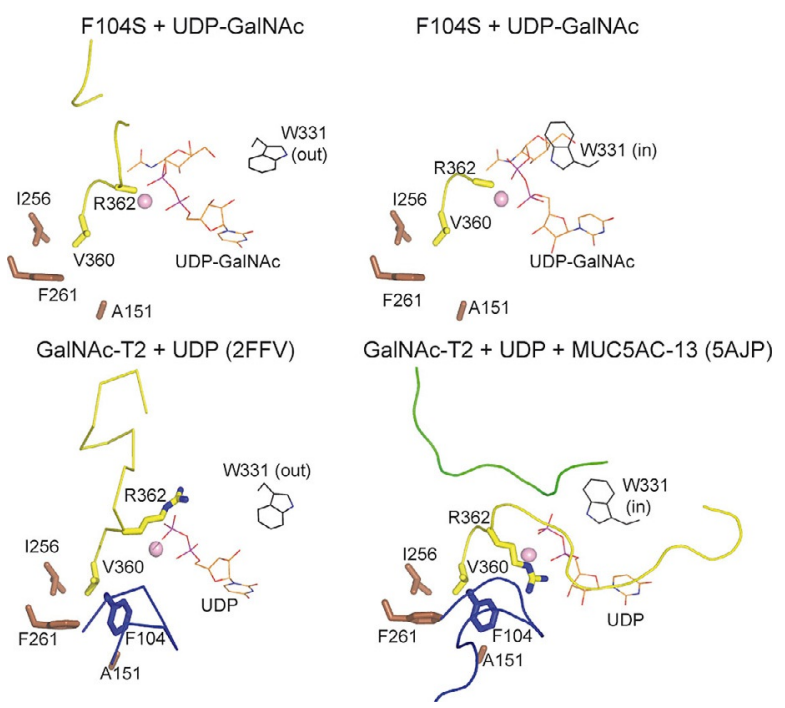

Figure 4. Close-up view of the complete sugar nucleotide and partial peptide-binding site of the complexes in Figure 3. Phe104, the residues interacting with Phe104, Val360/Arg362, and the Trp331 are shown in blue, brown, yellow and black carbon atoms, respectively. Both Phe104 and residues interacting with it are magnified. Trp331 is shown in out and in conformations. Notably, Trp331 in both F104S molecules present in the AU shows out and in conformations. residues, leading to destabilization of the $\alpha 1-\alpha 2$ loop and the inability of the flexible loop to reach the closed conformation. Therefore, the obtained data suggest that, if Phe104 is replaced by a serine residue (Ser104), the enzyme is not able to reach the active state, even in the presence of UDP-GalNAC due to the lack of essential Phe104/Arg362 CH- $\pi$ interactions, which provide additional stabilization required to induce the closed conformation of the flexible loop. Interestingly, most of the residues interacting with Phe104 and Ile256/Val360/ Phe261/Arg362, are highly conserved among different GalNAcTs (Figure $\mathrm{S} 6$ in the Supporting Information). This fact suggests that the flexible loop behavior and corresponding activation mechanism through the Phe104/Arg362 $\mathrm{CH}-\pi$ interaction is conserved across most GalNAc-T isoenzymes.

Regarding UDP-GalNAc recognition, the binding sites of both the F104S mutant and WT enzyme in the active form show almost equivalent interactions; this explains similar $K_{d}$ values obtained for this sugar nucleotide (Figure $2 \mathrm{~b}$ ). The interactions with UDP-GalNAc are mostly based on hydrogen bonds with the surrounding protein residues, whereas the pyrophosphate is involved in coordination of the $\mathrm{Mn}^{2+}$ ion, together with the residues of the $\mathrm{D}_{224} \mathrm{xH}_{226}$ motif and His359 (Figure 5). Minor additional interactions are found for the WT enzyme in the active form (e.g., hydrogen-bond interactions with Gly332 and Tyr367; Figure 5), which is in agreement with
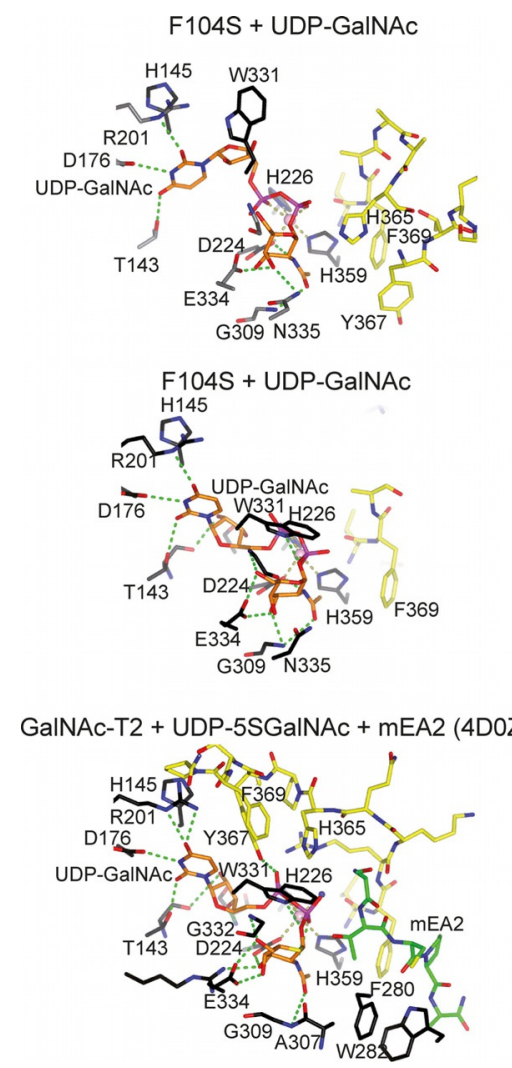

Figure 5. Close-up view of the sugar nucleotide and peptide binding site of the F104S-UDP-GalNAC and WT-UDP-5S-GalNAc-mEA2 complexes. Residues and the sugar nucleotides are depicted in the same colors as those shown in Figures 3 and 4. Hydrogen-bond interactions are shown as dotted green lines. 
the slightly better affinity for UDP-GalNAc on the WT enzyme versus the mutant (1.7-fold).

\section{Large conformational changes in the flexible loop in the F104S mutant}

To understand how the F104S mutation disturbs the dynamics of the flexible loop, we ran $200 \mathrm{~ns}$ MD simulations in explicit water on both the WT enzyme and the F104S mutant in the presence of UDP-GaINAc. Data revealed that the flexible loop of the mutant displayed significantly larger conformational changes, with root-mean-square deviations (RMSDs) ranging from 1 to $5.3 \AA$, compared with deviations of $1-3 \AA$ for the WT enzyme (Figure $6 \mathrm{a}$ ). This trend was also shown in the variation of $\mathrm{C} \alpha$ distances between the Phe104/Ser104 residues and Val360. Although a shorter distance of $(5.7 \pm 1.4) \AA$ was found for Phe104-Val360, highly variable and larger distances (ranging from 4.5 to $16 \AA$ ) were found for Ser104-Val360 (Figure $6 \mathrm{~b}, \mathrm{c})$. We also determined the distance distributions for Arg362/Phe104 and Arg362/Ser104-C $\alpha$ pairs (Figure 6b). The average distance of $(4.7 \pm 1.4) \AA$ found for the WT enzyme suggests the presence of stabilizing hydrophobic interactions between the aromatic ring of Phe104 and the side chain of Val360. In contrast, two populations were found for the mutant: a minor population, with distances ranging from 3.5 to $7 \AA$, and a major population, with highly oscillating distances, between 7.5 and $17 \AA$ (Figure $6 \mathrm{~b}$ ). These results also indi- cate that the flexible and $\alpha 1-\alpha 2$ loops are much more structured in the WT enzyme than those in the mutant and that these structural entities remain at a closer distance in the WT enzyme than that in the mutant. Therefore, according to MD analysis, the closed conformation of the flexible loop in the inactive mutant would rarely form.

\section{${ }^{19} \mathrm{~F}$ labeling of the T375C and F104S-T375C variants for NMR spectroscopy experiments}

To experimentally monitor the dynamics of the flexible loop, we also performed ${ }^{19} \mathrm{~F}$ NMR spectroscopy experiments on the WT enzyme and on the F104S mutant. ${ }^{19} \mathrm{~F}$ NMR chemical shifts are highly sensitive to changes in the local conformational environment and provide a simple and well-established approach for studying biomolecular structure, conformation, and dynamics. ${ }^{[11]}$ To introduce the required ${ }^{19} \mathrm{~F}$ label, Thr375 was mutated to the more nucleophilic Cys residue, in both the WT enzyme and the F104S mutant. This residue was selected for several reasons: 1) it is exposed and accessible for modification, and WT GaINAc-T2 and the F104S mutant contain only two free buried cysteines at the active site; 2 ) it is fairly close to the flexible loop, but sufficiently far away from the $\mathrm{Mn}^{2+}$ ion to minimize strong paramagnetic relaxation enhancements; and 3) crystallographic analyses indicate that Thr375 would be sensitive to flexible loop dynamics and may adopt different conformations, depending on the geometry of the flexible loop

a) residues of the flexible loop (Val360-Gly372)

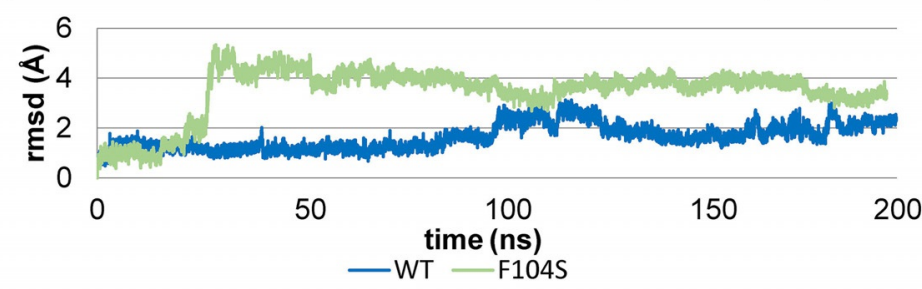

b)
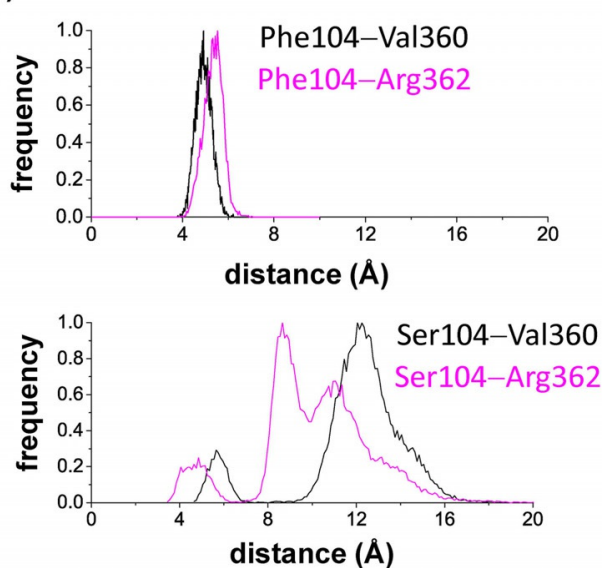

c)

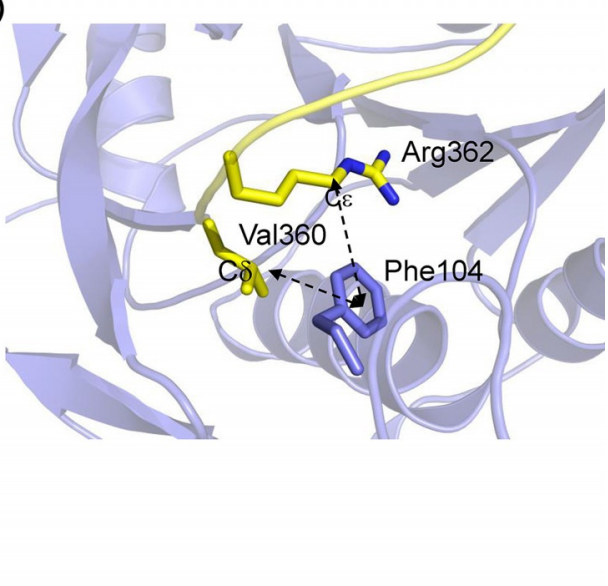

Figure 6. MD simulations on the WT enzyme and the F104S mutant. a) The RMSD values calculated from 200 ns MD simulations for the flexible loop indicate that this structural motif is more flexible in the mutant (green) than that in the WT enzyme (blue). Notably, the RMSD was obtained by using the fixed coordinates of the flexible loop from PDB entry 4D0T. b) This is also evidenced by a larger distance distribution between Ser104 (C $\alpha$ ) and Val360 (C $\delta) / A r g 362(C \varepsilon)$ in the mutant (bottom) relative to the corresponding distances (Phe104-Val360 and Phe104-Arg362) found in the WT enzyme (top). c) The center of mass of the $\pi$-electron system of Phe104 used to calculate the distances. 
(open or closed). It should be noted that Thr375 in PDB entry 2FFV is $10 \AA$ away from the same residue in PDB entry 5AJP (Figure $7 \mathrm{a}$ ). Thus, both the WT enzyme and the F104S mutant variants containing the $\mathrm{T} 375 \mathrm{C}$ mutation were produced (see the Experimental Section). The ${ }^{19} \mathrm{~F}$ label was subsequently introduced into the T375C and F104S-T375C variants by using BFA (see the Experimental Section). ${ }^{[1]} \mathrm{A}$ single $\mathrm{SCH}_{2}(\mathrm{CO}) \mathrm{CF}_{3}$ adduct was obtained for each enzyme (GalNAC-T2* and F104S*), as shown by trypsin digestion and MS fragmentation studies (Figure $7 \mathrm{~b}$ ). Although GalNAc-T2* was $100 \%$ labeled, F104S* was only $93 \%$ modified (Figure $7 \mathrm{~b}$ ). The activity of GalNAc-T2* was evaluated and compared with that obtained for the WT enzyme (Figure 7c and the Experimental Section). GalNAc-T2* still remained active, giving about $50 \%$ activity against MUC1 peptide, relative to the WT enzyme.

a)

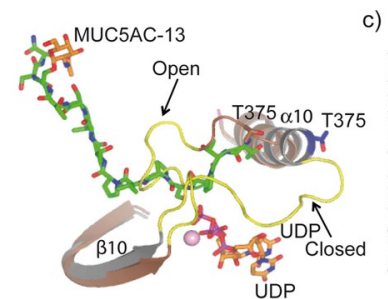

c)

b)
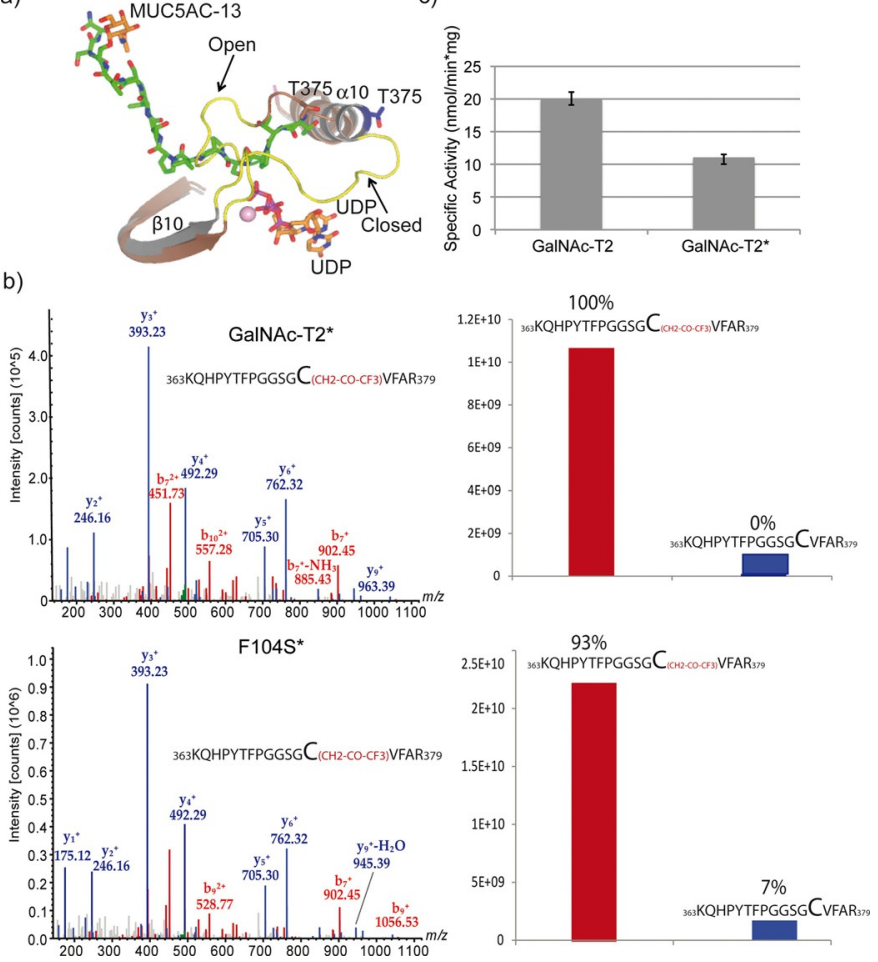

Figure 7. Labeling of the T375C and F104S-T375C variants with 3-bromo1,1,1-trifluoroacetone (BFA). a) Close-up view of the active sites of PDB entries 2FFV and 5AJP, which are in inactive and active states, respectively. The flexible loop adopting an open (2FFV) and closed conformation (5AJP) is colored in yellow. MUC5AC-13 is depicted as sticks in green carbon atoms, whereas the GalNAc moiety is in orange carbon atoms. UDP is colored in orange. The $\alpha$ and $\beta$ secondary structures are brown and gray for PDB entries 2FFV and 5AJP, respectively. Thr375 is depicted as sticks with brown $(2 \mathrm{FFV})$ and blue (5AJP) carbon atoms. Notably, DSSP ${ }^{[12]}$ extracts from the $3 \mathrm{D}$ structure reveal that Thr375 in PDB entry 2FFV is part of the flexible loop, whereas in PDB entry 5AJP it is located in $\alpha 10$. b) MS/MS spectrum of the precursor ions at $m / z 654.6346, z=3+$, assigned to

${ }_{363}$ KQHPYTFPGGSGCVFAR $_{379}$ peptide containing the ${ }^{19} \mathrm{~F}$ label at position $\mathrm{C} 375$ (left), and relative quantification based on the extracted ion chromatogram between peptides with and without the ${ }^{19} \mathrm{~F}$ label at position C375 (right). The experiments were performed for GalNAc-T2* (top) and F104S* (bottom). c) Specific activity of the WT enzyme and GaINAc-T2* by using the MUC1 peptide as an acceptor substrate. The data represent means \pm standard deviation (S.D.) for three independent experiments.
${ }^{19} \mathrm{~F}$ NMR spectroscopy experiments to reveal that GaINAc-T2 adopts a UDP-GalNAc-dependent induced-fit mechanism

With both WT and mutant proteins labeled with BFA, we first screened the enzyme activity against MUC5AC by means of ${ }^{1} \mathrm{H}$ NMR spectroscopy experiments, which confirmed that only GalNAC-T2*, and not the F104S* mutant, was able to glycosylate MUC5AC (Figures S7 and S8 in the Supporting Information).

To evaluate whether the Cys $375{ }^{19} \mathrm{~F}$ label was sensitive to the dynamics of the flexible loop upon substrate binding, we first performed ${ }^{19} \mathrm{~F}$ NMR spectroscopy experiments on GalNAcT2* A set of experiments with distinct combinations of UDPGalNAC, $\mathrm{MnCl}_{2}$, and MUC5AC were used (Figure 8, left and middle panels, and Figures S9 and S10 in the Supporting Information). The ${ }^{19} \mathrm{~F}$ NMR spectra of unbound GalNAc-T2* (Figure 8, left and middle panels, blue) showed two ${ }^{19} \mathrm{~F}$ resonances at $\delta=-84.0$ and $-84.3 \mathrm{ppm}$. The upfield ${ }^{19} \mathrm{~F}$ signal at $\delta=-84.3 \mathrm{ppm}$ remained unperturbed for all combinations of added substrates, which we attribute to the oligomeric GalNAc-T2* state. The line width of the upfield oligomer ${ }^{19} \mathrm{~F}$ signal $(\delta=-84.3 \mathrm{ppm})$ is $161 \mathrm{~Hz}$, which is significantly larger than that observed for the monomer at $\delta=-84.0 \mathrm{ppm}$ $(111 \mathrm{~Hz})$; this is consistent with a reduced relaxation time of the oligomeric enzyme. ${ }^{[13]}$ We have previously demonstrated, by small-angle $\mathrm{X}$-ray scattering experiments, that GalNAc-T2 forms oligomers that are not fully catalytically active. ${ }^{[5]}$ This may explain the lack of perturbation of this particular NMR signal under different substrate combinations. After addition of UDP-GalNAc and $\mathrm{Mn}^{2+}$ to GalNAc-T2*, the ${ }^{19} \mathrm{~F}$ NMR resonance at $\delta=-84.0 \mathrm{ppm}$ almost vanished and a new signal appeared at $\delta=-83.7 \mathrm{ppm}$ (Figure 8 , left and middle panels, red). It is remarkable that exchange between these two ${ }^{19} \mathrm{~F}$ NMR resonances $(\delta=-84.0$ and $-83.7 \mathrm{ppm}$ ) only occurs in the presence of UDP-GalNAc and $\mathrm{Mn}^{2+}$. Indeed, in the absence of UDPGalNAc, the addition of $\mathrm{Mn}^{2+}$ (Figure 8, left and middle panels, green) or the peptide MUC5AC (Figure 8, left and middle panels, gray) did not induce any appreciable perturbation in the ${ }^{19} \mathrm{~F}$ NMR spectrum of GalNAc-T2*. This result strongly suggests that the ${ }^{19} \mathrm{FNMR}$ resonances at $\delta=-84.0$ and $\delta=$ $-83.7 \mathrm{ppm}$ correspond to the open and closed conformations of the flexible loop, respectively. These two populations are in slow exchange on the NMR chemical shift timescale, and thus, detected as two resonances. An additional set of experiments was also recorded in the presence of UDP and $\mathrm{Mn}^{2+}$ (Figure S11 in the Supporting Information), giving similar results to those obtained for addition of UDP-GalNAc. However, exchange between the open and closed conformations of the flexible loop was not as pronounced as that in the presence of UDP-GalNAc. Altogether, our data show that UDP-GalNAc is vital for the interconversion between the open and closed conformations of the flexible loop, and that UDP-GalNAc stabilizes the closed conformation better than UDP (see Figures S9-S11 in the Supporting Information). As deduced from analysis of the crystal structure (see Figure 5 and panel corresponding to the active site of the PDB entry 4D0Z), UDP-GalNAc displays additional interactions with the enzyme through the GaINAC 


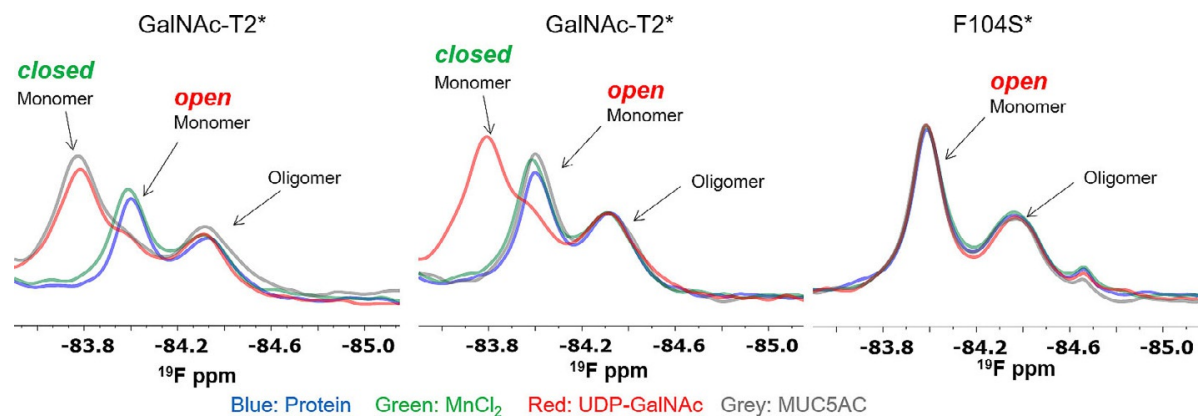

Figure 8. ${ }^{19} \mathrm{~F}$ NMR spectra of GalNAC-T2* and F104S* showing the open and closed loop conformations as a function of donor and acceptor substrate additions. Left: Blue, unliganded GalNAc-T2*; green, GalNAc-T2* in the presence of $\mathrm{MnCl}_{2}(225 \mu \mathrm{M})$; red, GalNAc-T2*, MnCl 2 (225 $\left.\mu \mathrm{M}\right)$, and UDP-GaINAc (225 $\left.\mu \mathrm{M}\right)$; gray, GalNAc-T2*, MnCl $(225 \mu \mathrm{M})$, UDP-GalNAc $(225 \mu \mathrm{M})$, and MUC5Ac (150 $\mu \mathrm{m})$. Middle: Blue, unliganded GalNAc-T2*; gray, GalNAc-T2* and MUC5AC $(150 \mu \mathrm{M})$; green, GalNAc-T2*, MUC5AC $(150 \mu \mathrm{M})$, and $\mathrm{MnCl}_{2}(225 \mu \mathrm{M})$; red, GalNAc-T2* $(135 \mu \mathrm{M}), \mathrm{MUC}^{*} \mathrm{Ac}(150 \mu \mathrm{M}), \mathrm{MnCl}_{2}(225 \mu \mathrm{M})$, and UDP-GalNAc $(225 \mu \mathrm{M})$. Right: Blue, unliganded $\mathrm{F} 104 S^{*}$; green, $\mathrm{F}_{104 S^{*}}$ and $\mathrm{MnCl}_{2}(130 \mu \mathrm{M})$; red, $\mathrm{F} 104 \mathrm{~S}^{*}, \mathrm{MnCl}_{2}(130 \mu \mathrm{M})$, and UDP-GalNAc (130 $\left.\mu \mathrm{M}\right)$; gray, $\mathrm{F} 104 \mathrm{~S}^{*}$, $\mathrm{MnCl}_{2}(130 \mu \mathrm{M})$, UDP-GalNAC $(130 \mu \mathrm{M})$, and MUC5Ac $(100 \mu \mathrm{M})$. The concentrations of GalNAc-T2* and F104S were 135 and $86 \mu \mathrm{M}$, respectively. The experiments were recorded at $298 \mathrm{~K}$ and $600 \mathrm{MHz}$ (see the Experimental Section).

moiety. The fact that UDP does not completely exchange the population of the enzyme conformations towards the fully active state is consistent with its role as a reaction product after catalysis.

The ${ }^{19} \mathrm{~F}$ NMR spectroscopy experiments provide compelling evidence that GalNAc-T2 follows an induced-fit mechanism and supports our previously proposed ordered bi-bi kinetic mechanism for this enzyme. ${ }^{[6 c]}$ The induced-fit mechanism has also been proposed for distant glycosyltransferases, such as B4GALT1 and the lactose synthase, by applying X-ray crystal structure studies. ${ }^{[14]}$ In this mechanism, GalNAc-T2 is always in the inactive state (open flexible loop) and only exchanges to the active state (closed flexible loop) in the presence of UDPGalNAc/ $\mathrm{MnCl}_{2}$. In contrast to the earlier hypothesis, ${ }^{[6 c]}$ our new data does not support the existence of an equilibrium between the inactive and active states in the absence of UDPGalNAc/ $\mathrm{MnCl}_{2}$. The uridine moiety of UDP-GalNAc might also shift its orientation from the inverted conformation to the typical geometry required for catalysis during the transition from the inactive to the active state of the enzyme. Only after the enzyme is in the active state can the peptide bind and catalysis take place.

\section{The inactive-to-active state transition of the flexible loop is hindered in the F104S mutant}

The same set of experiments was performed for the F104S* construct (Figure 8, right panel, and Figures S12 and S13 in the Supporting Information). In this case, no alterations in the ${ }^{19} \mathrm{~F}$ NMR spectrum were observed for any substrate addition. In particular, the addition of UDP-GalNAc or UDP did not induce any perturbation of the ${ }^{19} \mathrm{~F}$ resonance at $\delta=-84.0 \mathrm{ppm}$ (Figure 8 and Figures S12 and S13 in the Supporting Information). This result also confirms the assignment of the signal at $\delta=-84.0 \mathrm{ppm}$ to the open conformation of the flexible loop and highlights that this conformation is associated with the inactive form of GalNAc-T2. Furthermore, the ${ }^{19} \mathrm{~F}$ NMR spectroscopy experiments demonstrate that the flexible loop in F104S* is fixed in the open conformation, which precludes binding to peptide substrates and their glycosylation. Overall, the ${ }^{19} \mathrm{~F}$ NMR spectroscopy experiments provide the molecular basis to explain why the F104S mutant does not recognize peptides and, in turn, is inactive.

\section{Conclusion}

Studies of naturally occurring mutations in glycosyltransferases that underlie human diseases or predispositions to diseases or other phenotypes have brought important insights into our understanding of this diverse group of enzymes. ${ }^{[15]}$ In particular, studies of mutations that are not clear in how they affect protein structure and function have resulted in surprising new discoveries. From this perspective, our studies on the GalNAcT2 F104S mutant provide another excellent example. Herein, we provide compelling evidence that the inactive-to-active state transition of the flexible loop in the GalNAc-T2 F104S mutant is hindered. The presence of the polar residue (Ser104) causes instability of both the flexible and $\alpha 1-\alpha 2$ loops and prevents the flexible loop from adopting the closed conformation required for the active form of the enzyme. This result is further supported by the conservation of the Phe104, Val360, and Arg362 residues of the flexible loop in most GalNAc-Ts. We also predict that this behavior of the flexible loop will be conserved among this family of enzymes, despite their different lengths and partially different amino acid sequences. Our study has also experimentally demonstrated, from our ${ }^{19} \mathrm{~F}$ NMR spectroscopy studies, that GaINAc-T2 follows an induced-fitmechanism, in which UDP-GalNAc is essential to activate the enzyme.

The finding that the GalNAc-T isoenzymes undergo an activation process induced by the donor substrate UDP-GaINAC may be an important factor in the regulation of the complex O-glycosylation process. The GalNAc-T isoenzymes not only have different, albeit partly overlapping, acceptor substrate specificities, ${ }^{[9]}$ but they also exhibit rather different apparent $K_{\mathrm{m}}$ values for UDP-GalNAc, ranging from 10 to $160 \mu \mathrm{m}$ for GalNAc$\mathrm{T} 1, \mathrm{~T} 2, \mathrm{~T} 3$, and T4. ${ }^{[16]}$ Provided that all GalNAc-T isoenzymes undergo similar donor-induced activation, existing differences in 
affinities for the donor may serve as a regulatory mechanism to ensure that the many isoenzymes act in a required order and without a premature competitive binding to the acceptor proteins. This hypothesis is also supported by lower $K_{\mathrm{m}}$ values for UDP-GaINAc of the first enzymes that are thought to initiate the O-glycosylation process, GalNAc-T1 and T2. These enzymes display low apparent $K_{\mathrm{m}}$ values ( 27 and $10 \mu \mathrm{M}$, respectively), whereas isoenzymes involved in the follow-up glycosylation of the partially (GalNAc) glycosylated substrates, for example, GalNAc-T4, show a much higher apparent $K_{\mathrm{m}}$ for UDPGalNAc $(160 \mu \mathrm{m}) .{ }^{[16]}$

The hexosamine biosynthetic pathway (HBP) regulates the cellular levels of UDP-GIcNAc, and the cellular levels of UDPGalNAc are coregulated with UDP-GICNAc through epimerization by UDP-Gal/UDP-GalNAc 4-epimerase. ${ }^{[17]}$ Because the levels of UDP-GICNAc are highly dynamic, HBP is regarded as a nutrient-sensing pathway. ${ }^{[18]}$ Therefore, it is conceivable that the nutrient-sensing pathway may also influence O-GalNAc glycosylation through changes in UDP-GalNAc concentration.

Finally, our results have exploited knowledge obtained from structural analysis of a mutant associated with a known disease to obtain fundamental insights into the molecular mechanism of the GalNAc-T substrate recognition. Our multidisciplinary approach may furthermore provide the basis to treat low HDL-C levels through the design and implementation of new therapeutic strategies.

\section{Experimental Section}

\section{Cloning, site-directed mutagenesis, and purification}

The expression plasmid pPICZaAgalnact2 (K75-Q571) previously described $^{[6 c]}$ was used as a template for introducing the following single amino acid changes by site-directed mutagenesis: T375C, F104S, and F104S-T375C. Site-directed mutagenesis was carried out by using the QuikChange protocol (Stratagene), as recommended by the supplier. In brief, F104S mutation was introduced into the GALNT2 codon optimized with the K75-Q571 open reading framework (ORF) by using the template pPICZaAgalnact2 (K75Q571) and the oligomers T2F104SF (3'-TACGCAAGAAATAAGTCTAATCAGGTTGAAAGTGATAA-3') and T2F104SR (5'-TTATCACTTTCAACCTGATTAGACTTATTTCTTGCGTA-3'), generating the plasmid pPICZ $\alpha$ Agalnact2-F104S. The position of the mutation is underlined in the above oligomers. Hereafter, the mutation T375C was introduced by means of the custom-based mutagenesis service from Genewiz to generate pPICZ $\alpha$ Agalnact2-T375C and pPICZ $\alpha$ Agalnact2-F104S/T375C. The expression plasmid pPICZaAgalnact2 (K75Q571) previously described ${ }^{[6 c]}$ was used as a template for introducing the following single amino acid changes by site-directed mutagenesis: F104S, T375C, and F104S-T375C. Site-directed mutagenesis was carried out by following the QuikChange protocol (Stratagene), with the Phusion Hot Start II high-fidelity DNA polymerase (Thermo Scientific). All plasmids were verified by sequencing. The mutants were purified by using the purification protocol of the WT enzyme described previously. ${ }^{[6]]}$

\section{Crystallization}

Crystals of the F104S mutant in complex with UDP were grown by sitting drop vapor diffusion at $18^{\circ} \mathrm{C}$. Crystals were obtained by mixing protein solution $\left(0.5 \mu \mathrm{L}\right.$; a mix formed by $7 \mathrm{mg} \mathrm{mL}^{-1} \mathrm{~F} 104 \mathrm{~S}$ mutant, $5 \mathrm{~mm}$ UDP, $5 \mathrm{~mm} \mathrm{MnCl}$, $25 \mathrm{~mm}$ Tris $\mathrm{pH} 7.5,0.5 \mathrm{~mm}$ ethylenediaminetetraacetic acid (EDTA) and $1 \mathrm{~mm}$ tris(2-carboxyethyl)phosphine hydrochloride (TCEP-HCI)) with precipitant solution $(0.5 \mu \mathrm{L} ; 10 \%$ polyethylene glycol 6000 (PEG6000) and $100 \mathrm{~mm}$ Hepes $\mathrm{pH}$ 7) against precipitant solution ( $60 \mu \mathrm{L}$ ). The crystals were soaked within the mother liquor containing UDP-GaINAc at $50 \mathrm{~mm}$ for $60 \mathrm{~min}$. Subsequently, they were cryoprotected in mother liquor containing $25 \%$ ethylene glycol, $10 \%$ PEG6000, and $100 \mathrm{~mm}$ Hepes at $\mathrm{pH} 7$, and frozen in a nitrogen gas stream cooled to $100 \mathrm{~K}$.

\section{Structure determination and refinement}

All data were processed and scaled by using the XDS package ${ }^{[19]}$ and CCP4 software; ${ }^{[20]}$ relevant statistics are given in Table S2 in the Supporting Information. The crystal structures were solved by molecular replacement with Phaser ${ }^{[20]}$ and by using PDB entry 4D0T as the template. Initial phases were further improved by cycles of manual model building in Coot and refinement with REFMAC5. ${ }^{[21]}$ The final models were validated with PROCHECK; ${ }^{[22]}$ model statistics are given in Table S2 in the Supporting Information. The AU of the tetragonal crystals contained two molecules of the inactive mutant in the $\mathrm{AU}$ (Figure 1). Coordinates and structure factors have been deposited in the Worldwide Protein Data Bank (wwPDB; see Table S2 in the Supporting Information for the PDB codes).

\section{Labeling of the mutants T375C and F104S-T375C}

Both T375C and F104S-T375C variants were site-selectively modified by treatment with BFA under mild conditions $(5 \mathrm{~min}$, phosphate buffer $\mathrm{pH} 7.0$, room temperature), as previously described by Rydzik et al. ${ }^{[11]}$

\section{Solid-phase peptide synthesis}

MUC5AC was synthesized as previously described. ${ }^{[5]}$

\section{Tryptophan fluorescence spectroscopy}

Fluorescence spectroscopy was used to determine the dissociation constants of the WT enzyme and F104S mutant against UDPGaINAc. All experiments were carried out in a Cary Eclipse spectrofluorometer (Varian) at $25^{\circ} \mathrm{C}$ with the WT enzyme and F104S mutant at $1 \mu \mathrm{M}$, and concentrations of UDP-GalNAC varying from 1 to $1000 \mu \mathrm{M}$ in $25 \mathrm{~mm}$ Tris, $150 \mathrm{~mm} \mathrm{NaCl}, 1 \mathrm{~mm} \mathrm{MnCl}$, pH 7.5. Fluorescence emission spectra were recorded in the $\lambda=300-400 \mathrm{~nm}$ range with an excitation wavelength of $\lambda=280 \mathrm{~nm}$ and slit width of $5 \mathrm{~nm}$. Data analysis was performed in Prism (GraphPad software) by considering a model with a single binding site [see Eq. (1), in which $F 0$ is the intrinsic fluorescence of the enzyme in the absence of quencher (Q), $F 1$ is the observed fluorescence at a given quencher concentration, $f_{\mathrm{a}}$ is the fractional degree of fluorescence, and $K_{\mathrm{d}}$ is the dissociation constant].

$$
1-\frac{\mathrm{F} 1}{\mathrm{~F} 0}=\frac{f_{\mathrm{a}}[\mathrm{Q}]}{K_{\mathrm{d}}+[\mathrm{Q}]}
$$

\section{Activity assay}

The WT GalNAc-T2 and GalNAc-T2* activities were tested by incubating $100 \mathrm{~nm}$ of each enzyme with $10 \mu \mathrm{M}$ MUC1 peptide ${ }^{[23]}$ and 
$20 \mu \mathrm{M}$ UDP- $\left[{ }^{14} \mathrm{C}\right]$ GalNAc $\left(2000 \mathrm{cpms} \mathrm{nm}^{-1}\right)$, in $25 \mathrm{~mm}$ cacodylate $\mathrm{pH} 7.4,10 \mathrm{~mm} \mathrm{MnCl} 2,0.25 \%$ Triton X-100. Excess UDP-GalNAc was separated from the glycosylated peptide by means of DOWEX 1 chromatography. The product was analyzed by scintillation counting.

\section{Thermal shift assays}

The protein unfolding process was monitored by using the environmentally sensitive dye ANS. Its quantum yield increased upon binding to hydrophobic surfaces exposed during protein unfolding, along with the fluorescence signal. The thermal shift assay was conducted by using a FluoDia T70 instrument (Photal Otsuka Electronics). Solutions of $2 \mu \mathrm{M}$ WT GalNAc-T2 or the F104S mutant, $100 \mu \mathrm{M}$ ANS, $20 \mathrm{~mm}$ HEPES at $\mathrm{pH} 7.0$, and $200 \mathrm{~mm} \mathrm{NaCl}$ final concentration in a volume of $100 \mu \mathrm{L}$ were added to the wells of a 96well polymerase chain reaction (PCR) plate. Finally, mineral oil was added to avoid evaporation during experiments. Data were analyzed with the Origin software. To obtain $T_{0}$, a Boltzmann model from Origin was used to fit the fluorescence imaging data. ${ }^{[8]}$

\section{MD simulations}

MD simulations were performed by using Amber16 and the forcefield ff14SB. ${ }^{[24]}$ Each protein was immersed in a box with a $10 \AA$ buffer of TIP3P $\mathrm{P}^{[25]}$ water molecules and neutralized by adding explicit counterions $\left(\mathrm{Cl}^{-}\right)$. A two-stage geometry optimization approach was used. The first stage minimized only the positions of solvent molecules and ions, and the second stage was an unrestrained minimization of all atoms in the simulation cell. The systems were then gently heated by increasing the temperature from 0 to $300 \mathrm{~K}$ under a constant pressure of $1 \mathrm{~atm}$ and periodic boundary conditions. Harmonic restraints of $30 \mathrm{kcal} \mathrm{mol}^{-1}$ were applied to the solute, and the Andersen temperature coupling scheme was used to control and equalize the temperature. The time step was kept at $1 \mathrm{fs}$ during the heating stages. Water molecules were treated with the SHAKE algorithm, such that the angle between the hydrogen atoms was kept fixed. Long-range electrostatic effects were modeled by using the particle mesh Ewald method. ${ }^{[26]}$ An $8 \AA$ cutoff was applied to Lennard-Jones interactions. Each system was equilibrated for $2 \mathrm{~ns}$ with a 2 fs time step at a constant volume and temperature of $300 \mathrm{~K}$. Production trajectories were then run for an additional $200 \mathrm{~ns}$ under the same simulation conditions.

\section{nLC-MS/MS and data analysis}

To preserve the trifluorinated compound at the peptide backbone, samples were not reduced and alkylated. GalNACT* and F104S* were directly digested with trypsin and, after StageTip (Empore $3 \mathrm{M})$ desalting, submitted to $\mathrm{nLC}-\mathrm{MS} / \mathrm{MS}$ analysis. EASY-nLC 1000 UHPLC (Thermo Scientific) interfaced through a nanoSpray Flex ion source to an Orbitrap Fusion mass spectrometer (Thermo Scientific) were used for analysis. Briefly, the $\mathrm{nLC}$ was operated in a single analytical column setup by using a PicoFrit Emitters column (New Objectives, $75 \mu \mathrm{m}$ inner diameter) packed in-house with ReprosilPure-AQ C18 phase (Dr. Maisch, $1.9 \mu \mathrm{m}$ particle size, 19-21 cm column length). Each sample was injected onto the column and eluted in a gradient from 2 to $25 \% \mathrm{~B}$ in $45 \mathrm{~min}$ at $200 \mathrm{~nL} \mathrm{~min}{ }^{-1}$ (Solvent A: $100 \% \mathrm{H}_{2} \mathrm{O}$; Solvent B, $100 \%$ acetonitrile; both containing $0.1 \%(\mathrm{v} / \mathrm{v})$ formic acid). A precursor MS1 scan $(\mathrm{m} / \mathrm{z} 350-2000)$ of intact peptides was acquired in the Orbitrap instrument at the nominal resolution setting of 120000 , followed by Orbitrap HCDMS2 and at the nominal resolution setting of 60000 of the five most abundant multiply charged precursors in the MS1 spectrum; a minimum MS1 signal threshold of 50000 was used for triggering data-dependent fragmentation events. Activation times were $75 \mathrm{~ms}$ for HCD fragmentation; the isolation width was 1.2 mass units, and usually 1 microscan was collected for each spectrum. Polysiloxane ions at $\mathrm{m} / \mathrm{z} 445.12003$ were used as a lock mass in all runs. Data processing was performed by using Proteome Discoverer 1.4 software (Thermo Scientific) with Sequest HT node as a search engine. In all cases, the precursor mass tolerance was set to $10 \mathrm{ppm}$ and fragment ion mass tolerance to $20 \mathrm{mmu}$. Methionine oxidation and the trifluorinated compound at Ser/Thr were used as variable modifications. All spectra were searched against GalNAcT2* and F104S* sequences with and without mutations at position 375 .

\section{NMR spectroscopy experiments}

NMR spectroscopy experiments for peptide characterization and STD-NMR spectroscopy experiments were recorded on a Bruker Avance $600 \mathrm{MHz}$ spectrometer equipped with a triple-channel cryoprobe head. The ${ }^{1} \mathrm{H}$ NMR resonances of the peptide were assigned through standard 2D-TOCSY ( 30 and $80 \mathrm{~ms}$ mixing time) and 2D-NOESY experiments ( $400 \mathrm{~ms}$ mixing time). Solution conditions used for the NMR characterization studies were $0.5 \mathrm{~mm}$ peptide in 90:10 $\mathrm{H}_{2} \mathrm{O} / \mathrm{D}_{2} \mathrm{O}$ mixture. The assignments were accomplished at $278 \mathrm{~K}$. As a chemical shift reference in the ${ }^{1} \mathrm{H}$ NMR spectroscopy experiments, we used the resonance of 2,2,3,3-tetradeutero-3-trimethylsilylpropionic acid (TSP; $\delta=0 \mathrm{ppm}$ ). Resonance lists for the 2D-TOCSY and 2D-NOESY spectra were generated by interactive signal picking by using the computer-aided resonance assignment (CARA) software. ${ }^{[27]}$ Table S1 in the Supporting Information contains the ${ }^{1} \mathrm{H}$ NMR spectroscopy assignments for the MUC5AC peptide. Samples for STD experiments were prepared in perdeuterated $25 \mathrm{~mm}\left[\mathrm{D}_{11}\right] \mathrm{TRIS}$ in deuterated water, $7.5 \mathrm{~mm} \mathrm{NaCl}$, and $1 \mathrm{~mm}$ 1,4-dithiothreitol (DTT), uncorrected $\mathrm{pH}$ 7.4. STD-NMR spectroscopy experiments were performed at $298 \mathrm{~K}$ in the presence of $75 \mu \mathrm{M}$ UDP and $75 \mu \mathrm{M} \mathrm{MnCl}_{2}$, with a molar ratio of 40:1 peptide/protein. The STD-NMR spectra were acquired with 1920 transients in a matrix with $64 \mathrm{k}$ data points in $\mathrm{t} 2$ in a spectral window of $12335.5 \mathrm{~Hz}$ centered at $2820.6 \mathrm{~Hz}$. An excitation sculpting module with gradients was employed to suppress the water proton signals. Selective saturation of the protein resonances (on resonance spectrum) was performed by irradiating at $\delta=-1 \mathrm{ppm}$ by using a series of Eburp2.1000-shaped $90^{\circ}$ pulses $(50 \mathrm{~ms} ; 1 \mathrm{~ms}$ delay between pulses) for a total saturation time of $2.0 \mathrm{~s}$. For the reference spectrum (off resonance), the samples were irradiated at $\delta=100 \mathrm{ppm}$. Proper STD-NMR control experiments were performed: 1) with the ligand in the absence of protein to ensure that the ligand signals were not affected; and 2) with the protein in the absence of ligand (data not shown). The peptide MUC5AC, upon irradiation at $\delta=-1 \mathrm{ppm}$ in the absence of protein, showed residual saturation on the aliphatic methyl groups in the STD-NMR spectra. The STD-NMR spectroscopy experiments shown herein take into account the STD control experiments. To obtain the STD-NMR-derived epitope mapping, the STD-NMR total intensities were normalized with respect the highest STD-NMR response. ${ }^{19} \mathrm{~F}$ NMR spectroscopy experiments were recorded by using a $600 \mathrm{MHz}$ Bruker Avance spectrometer equipped with a ${ }^{19} \mathrm{~F},{ }^{1} \mathrm{H}$ SEF dual probe optimized for direct ${ }^{19} \mathrm{~F}$ detection. These experiments were carried out to monitor the ${ }^{19} \mathrm{~F}$ reporter $\left(\mathrm{CF}_{3}\right)_{2} \mathrm{COCH}_{2}$ - selectively introduced at the $\mathrm{SH}-$ group of the $\mathrm{T} 375 \mathrm{C}$ mutants from both constructs of the WT GalNAc-T2 and F104S mutant. The ${ }^{19} \mathrm{~F}$ experiments of GalNAc$\mathrm{T}^{*}$ and $\mathrm{F} 104 \mathrm{~S}^{*}$ constructs were recorded under distinct conditions in the absence and presence of $\mathrm{MnCl}_{2}$, UDP or UDP-GalNAc, and peptide. The UDP or UDP-GaINAc and $\mathrm{MnCl}_{2}$ were added in an 
excess of 1.5 times of the protein concentration, whereas peptide was in a 1.1:1 molar ratio of peptide/protein. Higher concentrations of UDP or UDP-GalNAc $(500 \mu \mathrm{M}), \mathrm{MnCl}_{2}(500 \mu \mathrm{M})$, and peptide (1:2.2 molar ratio of protein/peptide) did not induce higher ${ }^{19} \mathrm{~F}$ chemical shift perturbations. The ${ }^{19} \mathrm{~F}$ NMR spectroscopy experiments with proton decoupling were acquired at $298 \mathrm{~K}$ through the acquisition of 640 scans in a matrix with $8 \mathrm{k}$ data points over a spectral window of $11295.2 \mathrm{~Hz}$ centered at $\left(\mathrm{CF}_{3}\right)_{2} \mathrm{CHOH}$ $-45174.9 \mathrm{~Hz}$. The resonance of 1,1,1,3,3,3-hexafluoro-2-propanol was used as a chemical shift reference in the ${ }^{19} \mathrm{~F}$ NMR spectroscopy experiments $\left(\delta=-75.7 \mathrm{ppm}\right.$ ). Samples for ${ }^{19} \mathrm{~F}$ NMR spectroscopy experiments were prepared in $25 \mathrm{mM}\left[\mathrm{D}_{11}\right] \mathrm{TRIS}$ in 90:10 $\mathrm{H}_{2} \mathrm{O} / \mathrm{D}_{2} \mathrm{O}$, uncorrected $\mathrm{pH} 7.5$. In the ${ }^{19} \mathrm{~F}$ NMR spectra, trace amounts of the BFA reagent used in protein labeling $\left(\delta_{\mathrm{CF}_{3} \mathrm{COCH}_{2} \mathrm{Br}}=-83.3 \mathrm{ppm}\right)$ were observed. In addition, trace amounts of trifluoroacetic acid (TFA), used in the synthesis of peptides, were observed in the ${ }^{19} \mathrm{~F}$ NMR spectra $\left(\delta_{\text {TFA }}=-75.4 \mathrm{ppm}\right)$. To monitor the glycosylation of MUC5AC by GalNAC-T2* and F1045*, two ${ }^{1} \mathrm{H}$ NMR spectra were recorded before and after the addition of UDP-GalNAc.

\section{Acknowledgements}

We thank the Ministerio de Economía y Competitividad (CTQ2013-44367-C2-2-P and BFU2016-75633-P to R.H-G., CTQ2015-67727-R to F.C., CTQ2015-64597-C2-1P to J.J-B). F.M. thanks FCT-Portugal for the IF project (IF/00780/2015) and UCIBIO funding UID/Multi/04378/2013 cofinanced by the FEDER (POCI-01-0145-FEDER-007728). The NMR spectrometers are part of PTNMR supported by project no. 022161 (co-financed by FEDER through COMPETE 2020, POCI and PORL and FCT through PIDDAC). H.C. thanks the Lundbeck Foundation and the Danish National Research Foundation (DNRF107). E.LN. acknowledges her postdoctoral EMBO fellowship ALTF 15532015 cofunded by the European Commission (LTFCOFUND2013, GA-2013-609409) and Marie Curie Actions. H.C. and J.J-B. thank the EU for the TOLLerant project. R.H-G. thanks the Agencia Aragonesa para la Investigación y Desarrollo (ARAID) and the Diputación General de Aragón (DGA, B89) for financial support. Research leading to these results has also received funding from the FP7 (2007-2013) under BioStruct-X (grant agreement no. 283570 and BIOSTRUCTX_5186). We thank synchrotron radiation source DIAMOND (Oxford) and beamline 104 (number of experiment MX10121-19). We would also like to thank to Prof. Tom Gerken for his valuable comments on our manuscript.

\section{Conflict of interest}

The authors declare no conflict of interest.

Keywords: enzymes - glycosylation - mutagenesis oligomers $\cdot$ structure-activity relationships

[1] C. Steentoft, S. Y. Vakhrushev, H. J. Joshi, Y. Kong, M. B. Vester-Christensen, K. T. Schjoldager, K. Lavrsen, S. Dabelsteen, N. B. Pedersen, L. Marcos-Silva, R. Gupta, E. P. Bennett, U. Mandel, S. Brunak, H. H. Wandall, S. B. Levery, H. Clausen, EMBO J. 2013, 32, 1478-1488.

[2] S. Fukumoto, Curr. Opin. Nephrol. Hypertens. 2014, 23, 346-351.
[3] K. Kato, C. Jeanneau, M. A. Tarp, A. Benet-Pages, B. Lorenz-Depiereux E. P. Bennett, U. Mandel, T. M. Strom, H. Clausen, J. Biol. Chem. 2006, 281, 18370-18377.

[4] S. A. Khetarpal, K. T. Schjoldager, C. Christoffersen, A. Raghavan, A. C. Edmondson, H. M. Reutter, B. Ahmed, R. Ouazzani, G. M. Peloso, C. Vitali, W. Zhao, A. V. Somasundara, J. S. Millar, Y. Park, G. Fernando, V. Livanov, S. Choi, E. Noe, P. Patel, S. P. Ho, T. G. Kirchgessner, H. H. Wandall, L. Hansen, E. P. Bennett, S. Y. Vakhrushev, D. Saleheen, S. Kathiresan, C. D. Brown, R. Abou Jamra, E. LeGuern, H. Clausen, D. J. Rader, Cell Metab. 2016, 24, 234- 245 .

[5] E. Lira-Navarrete, M. de Las Rivas, I. Companon, M. C. Pallares, Y. Kong, J. Iglesias-Fernandez, G. J. Bernardes, J. M. Peregrina, C. Rovira, P. Bernado, P. Bruscolini, H. Clausen, A. Lostao, F. Corzana, R. Hurtado-Guerrero, Nat. Commun. 2015, 6, 6937.

[6] a) M. Ghirardello, M. de Las Rivas, A. Lacetera, I. Delso, E. Lira-Navarrete, T. Tejero, S. Martin-Santamaria, R. Hurtado-Guerrero, P. Merino, Chem. Eur. J. 2016, 22, 7215-7224; b) R. Hurtado-Guerrero, Biochem. Soc. Trans. 2016, 44, 61-67; c) E. Lira-Navarrete, J. Iglesias-Fernandez, W. F. Zandberg, I. Companon, Y. Kong, F. Corzana, B. M. Pinto, H. Clausen, J. M. Peregrina, D. J. Vocadlo, C. Rovira, R. Hurtado-Guerrero, Angew. Chem. Int. Ed. 2014, 53, 8206-8210; Angew. Chem. 2014, 126, $8345-$ 8349.

[7] a) T. A. Fritz, J. H. Hurley, L. B. Trinh, J. Shiloach, L. A. Tabak, Proc. Natl. Acad. Sci. USA 2004, 101, 15307-15312; b) T. A. Fritz, J. Raman, L. A. Tabak, J. Biol. Chem. 2006, 281, 8613-8619; c) T. Kubota, T. Shiba, S. Sugioka, S. Furukawa, H. Sawaki, R. Kato, S. Wakatsuki, H. Narimatsu, J. Mol. Biol. 2006, 359, 708-727; d) M. L. Rivas, E. Lira-Navarrete, E. J. P. Daniel, I. Companon, H. Coelho, A. Diniz, J. Jimenez-Barbero, J. M. Peregrina, H. Clausen, F. Corzana, F. Marcelo, G. Jimenez-Oses, T. A. Gerken, R. Hurtado-Guerrero, Nat. Commun. 2017, 8, 1959.

[8] E. Lira-Navarrete, J. Valero-Gonzalez, R. Villanueva, M. Martinez-Julvez, T. Tejero, P. Merino, S. Panjikar, R. Hurtado-Guerrero, PLoS One 2011, 6, e25365.

[9] T. A. Gerken, O. Jamison, C. L. Perrine, J. C. Collette, H. Moinova, L. Ravi, S. D. Markowitz, W. Shen, H. Patel, L. A. Tabak, J. Biol. Chem. 2011, 286, $14493-14507$.

[10] J. Raman, T. A. Fritz, T. A. Gerken, O. Jamison, D. Live, M. Liu, L. A. Tabak, J. Biol. Chem. 2008, 283, 22942-22951.

[11] A. M. Rydzik, J. Brem, S. S. van Berkel, I. Pfeffer, A. Makena, T. D. Claridge, C. J. Schofield, Angew. Chem. Int. Ed. 2014, 53, 3129-3133; Angew. Chem. 2014, 126, 3193-3197.

[12] W. G. Touw, C. Baakman, J. Black, T. A. H. te Beek, E. Krieger, R. P. Joosten, G. Vriend, Nucleic Acids Res. 2015, 43, D364-D368.

[13] J. M. Aramini, K. Hamilton, L. C. Ma, G. V. T. Swapna, P. G. Leonard, J. E. Ladbury, R. M. Krug, G. T. Montelione, Structure 2014, 22, 515-525.

[14] B. Ramakrishnan, E. Boeggeman, P. K. Qasba, Biochem. Biophys. Res. Commun. 2002, 291, 1113-1118.

[15] H. H. Freeze, H. Schachter, T. Kinoshita in Essentials of Glycobiology, 3rd ed. (Eds.: A. Varki, R. D. Cummings, J. D. Esko, P. Stanley, G. W. Hart, M. Aebi, A. G. Darvill, T. Kinoshita, N. H. Packer, J. H. Prestegard, R. L. Schnaar, P. H. Seeberger), Cold Spring Harbor, New York, 2015.

[16] E. P. Bennett, H. Hassan, U. Mandel, E. Mirgorodskaya, P. Roepstorff, J. Burchell, J. Taylor-Papadimitriou, M. A. Hollingsworth, G. Merkx, A. G. van Kessel, H. Eiberg, R. Steffensen, H. Clausen, J. Biol. Chem. 1998, 273, $30472-30481$.

[17] a) B. A. Lewis, J. A. Hanover, J. Biol. Chem. 2014, 289, 34440-34448; b) J. B. Thoden, T. M. Wohlers, J. L. Fridovich-Keil, H. M. Holden, J. Biol. Chem. 2001, 276, 15131-15136.

[18] S. Marshall, V. Bacote, R. R. Traxinger, J. Biol. Chem. 1991, 266, $4706-$ 4712.

[19] W. Kabsch, Acta Crystallogr. Sect. D 2010, 66, 125-132.

[20] M. D. Winn, C. C. Ballard, K. D. Cowtan, E. J. Dodson, P. Emsley, P. R. Evans, R. M. Keegan, E. B. Krissinel, A. G. Leslie, A. McCoy, S. J. McNicholas, G. N. Murshudov, N. S. Pannu, E. A. Potterton, H. R. Powell, R. J. Read, A. Vagin, K. S. Wilson, Acta Crystallogr. Sect. D 2011, 67, 235-242.

[21] G. N. Murshudov, P. Skubak, A. A. Lebedev, N. S. Pannu, R. A. Steiner, R. A. Nicholls, M. D. Winn, F. Long, A. A. Vagin, Acta Crystallogr. Sect. D 2011, 67, 355-367.

[22] R. A. Laskowski, M. W. Macarthur, D. S. Moss, J. M. Thornton, J. Appl. Crystallogr. 1993, 26, 283-291. 
[23] H. H. Wandall, F. Irazoqui, M. A. Tarp, E. P. Bennett, U. Mandel, H. Takeuchi, K. Kato, T. Irimura, G. Suryanarayanan, M. A. Hollingsworth, H. Clausen, Glycobiology 2007, 17, 374-387.

[24] V. Hornak, R. Abel, A. Okur, B. Strockbine, A. Roitberg, C. Simmerling, Proteins Struct. Funct. Bioinf. 2006, 65, 712-725.

[25] T. A. Andrea, W. C. Swope, H. C. Andersen, J. Chem. Phys. 1983, 79, $4576-4584$

[26] T. Darden, D. York, L. Pedersen, J. Chem. Phys. 1993, 98, 10089-10092.
[27] R. Keller, The computer aided resonance assignment tutorial CARA, Goldau, Switzerland, Cantina Verlag, 2004.

Manuscript received: February 11, 2018

Accepted manuscript online: March 30, 2018

Version of record online: May 16, 2018 